\title{
LEARNING BASED ON CHALLENGES IN THE CONTEXT OF MULTIDISCIPLINARY TEAMWORK IN EHEALTH. AN EVALUATION OF THE STUDENTS' EXPERIENCE
}

\author{
A. Graells-Sans ${ }^{1}$, N. Castell-Ariño ${ }^{2}$, E. Insa-Caderón ${ }^{1}$ \\ ${ }^{1}$ Campus Docent Sant Joan de Déu (SPAIN) \\ ${ }^{2}$ Universitat Politècnica de Catalunya (SPAIN) \\ agraells@santjoandedeu.edu.es, castell@cs.upc.edu,einsa@santjoandedeu.edu.es
}

\begin{abstract}
Education in eHealth is becoming of transcendental importance in the European social context. The progressive aging of the population has generated an increase in the prevalence of people with disabilities who demand more effective, adapted and flexible services. Advances in computer science and technology are enabling a qualitative leap in the care of these people, offering solutions to health demands. However, the incorporation of technology in the field of health requires the acquisition of new skills.

The eHealth Eurocampus is an EU-funded Erasmus+ Strategic Partnership, whose primary aim is to support the development of innovative teaching materials and activities that will improve the relevance and quality of higher education in the field of eHealth. A total of 10 European institutions participate in the project, including universities, hospitals and technology companies.

We present the results corresponding to the third edition of the summer school that took place in Barcelona during the month of July 2019. On this occasion, the main topic was the use of robotics and medical imaging for the treatment of physical and cognitive disability. A teaching methodology based on the presentation of challenges was used and for which the different groups had to work and give a technological solution. The challenges were proposed by real patients and healthcare professionals who, from their experience, presented a problem of their daily life: they went from issues related to the mobility of people with physical disabilities to the usability of medical devices in hospital settings. The students were organized in multi-disciplinary and multicultural teams, and they had to develop their prototypes to respond to the proposed challenge. The resulting projects were presented publicly to the patients and professionals themselves for further discussion.
\end{abstract}

The results presented refer to the perceptions of participating students about the effectiveness of this methodology in the training of skills and competences for multidisciplinary work. In general, the adequacy of the methodology for the described objective is verified. Students highlight the importance of soft skills training in this type of context. Communication has appeared as the most important competence. Some students have mentioned that one of the great challenges encountered was to understand each other among the different backgrounds. However, they consider that the effort involved in having to reason their positions with understandable terms for all team members has improved their communication and conflict resolution skills. Another of the strengths that stand out in the results is the fact that the project was raised from real cases. However, the students identify as an aspect of improvement a greater interaction with the people who propose the challenges to validate the proposed solution during the development process of the project, and not only at the end.

In conclusion, the results demonstrate the effectiveness of experiences of this type in the training of skills necessary for work in the context of digital health. It is important to incorporate initiatives of this type in the current university degrees for greater adaptation of training to the needs and demands of the social and professional context.

Keywords: Teamwork, eHealth, multidisciplinary, challenge 


\section{INTRODUCTION}

In the last decades, the European context is experiencing an unprecedented demographic challenge to date; while life expectancy is increasing year after year along with an increase in quality of life, fertility rates are suffering from a drop that places them below the level of replacement. This translates into a slowdown in population growth and an acceleration of global aging. European strategies to address this situation point to the promotion of active and healthy aging as one of priority policies. This challenge provides a unique opportunity to re-think creative and innovative strategies that promote the health and independence of these groups. Advances in technology and digital health must allow not only improving the quality of health services but also facilitating access to these services to a greater number of people [1], [2], [3].

The eHealth discipline is relatively new in university education and, therefore, it is still looking for the best strategies and methodologies to prepare the professionals that will be devoted to it in the future. To do this, it is necessary to test them and validate their effectiveness.

Focusing on eHealth work and learning we identify different aspects of professional development to take into account. On the one hand, at a time when the movement of professionals between different countries has increased [4], it is increasingly necessary to acquire skills and competencies to work in multicultural work environments.

On the other hand, one of the keys to work in eHealth is interdisciplinary work [5], [6], [7] since these tasks will necessarily require the confluence and cooperative work of different disciplines and professions. This training raises many challenges for the strategies that have traditionally been used, who have rarely resorted to other disciplines to complement their own training. The motivation for the training of interdisciplinary skills responds to the interest of generating a new knowledge that is the product of the interaction of both disciplines, and not merely the addition of different concepts and abilities and, at the same time, they are mutually nourished.

Finally, in traditional training, academic work often uses reality-like situations, but rarely the users and / or community participate in a way that can collaborate with students to create a realistic solution. In the specific case of the field of eHealth, references have been found on how to train to a be an eHealth literate [8] but no initiatives have been found in which both patients and students of health and technology background has collaborated for the reflection and creation of technological solutions to respond to the real problems of the participating population and that can have a continuity beyond the academic period.

To respond to emerging European social and health needs, the eHealth Eurocampus Summer School project was created to help train eHealth professionals of the future, empowering them with knowledge and skills that support a society which will increasingly need high-quality, reliable and credible technologies that are acceptable to both patients and clinical professionals [9] .

The project lasted 3 years and a total of 10 European institutions, including universities, hospitals and technology companies, participated. During the 3 years of the project, a series of teaching materials have been created and tested in the different summer schools that have been organized with students from different nationalities and disciplines, including: ICT, Engineering, Nursing, Medicine, Business and Occupational Therapy.

Aside from the materials created, summer schools have served to test different teaching methodologies and thus to see the perception of students and the effectiveness of them [10]. Therefore, in the first Summer school, where the subject of entrepreneurship was used, we tested methodologies based on co-creation for the design and presentation of innovative solutions; In the second health school, the theme was the aging and the use of mobile applications. In this the contents were worked through the use of the simulation methodology with professional actors that allowed to train the design centered on the person, the creation of a prototype and its validation with the user; Finally, in the third Summer School (whose results are presented in this article), it turned on the topics of robotics and medical imaging applied to the field of physical disability and we opted for the use of the methodology of work for challenges.

The pedagogical approach known as challenge-based learning (CBL) [11] is a pedagogical approach that actively involves the student in a real, relevant and engaging problem situation with the environment, which implies defining a challenge and the implementation of a solution [12]. In addition, they are 
characterized by being open-ended nature. Therefore, the CBL is an approach that implies the student in a real problem linked to his context and where the challenge is understood as the activity, task or situation that causes a stimulus that motivates him to seek an answer. This approach allows the use of technology to solve the real problems of its environment. Thus, we selected 9 real challenges that were selected and presented to students in a format that we have called video-challenge.

The aim of this article is to present the results of the application of the video-challenges methodology corresponding to the third edition of the summer school that took place in Barcelona during the month of July 2019.

\section{METHODOLOGY}

After the experience of using and evaluating different teaching methodologies in eHealth training, the third Summer School of the project opted for the use of learning based on challenges in video format where challenges were launched to students by patients and health professionals. The purpose was to respond to some of the needs with which we had met in other editions. Thus, for example, with the use of video challenges, the problems were presented by the same people who needed a solution and, moreover, that they did using their language, without the teacher having to intervene or act of intermediary. This meant that there was, necessarily, a relationship and communication between them in order to respond in a collaborative way to the situations posed. Likewise, it promoted a student's autonomous working time as well as work tutored by the teacher. Finally, it was sought that students verify the relevance and usefulness of their work, in order to achieve greater motivation and commitment in the workplace and avoid that they ended up locked in a drawer once finalized, like happens very often with academic works.

\subsection{Selection of the challenges and design of video-challenges:}

Once the methodology was selected and clearly justified, the 6 teaching coordinators of the 3rd edition of the summer school (2 technologists and 4 healthcare professionals) made the calculation of the necessary sample, which was intentional, defined the inclusion and exclusion criteria to volunteer and devised a search and contact strategy with patients and health professionals related to physical or cognitive disability.

The calculation of the necessary number of volunteers to carry out the methodology was carried out taking into account the maximum number of students admitted to the course (63) and the maximum number of students recommended by group for this type of methodologies (between 6 and 8 ). In order to be able to volunteer and participate challenging students, it was necessary to have a physical or cognitive disability diagnosed or to be a health professional that work daily in contact with disabled people or with functional diversity. Regarding the volunteer search strategy, the snowball was used, and the contact was made through different means, being the most used the telephone call and the email. A draft information document was drafted to describe the project and an informed consent document was created to be signed by all volunteers or participants. The basic video-challenge criteria were also specified so that they all followed the same format. It is noteworthy that in the selection of the volunteers, we tried to find the maximum pathological or professional variability so that the sample was the maximum representative of the disability landscape.

Once the sample was selected, it took a period of one month to present the video-challenge proposal. It obtained the participation of 8 volunteers who presented a total of 9 challenges (one of the volunteers presented two challenges in the same video). Once collected, the coordinating team edited the videos and subtitled those recorded in another different language than English.

\subsection{Implementation of the activity:}

The video-challenges activity was presented on the first day of the eHealth Eurocampus Summer school. Throughout one afternoon the groups of students were established, which were tried to be heterogeneous in terms of country of origin and training (it was tried that there was a student of each institution and an equitable distribution of disciplines). All video-challenges were presented in the 
classroom and each group, after a discussion about the pros and cons, could choose the one they wanted to work on. In the event that two teams decided to carry out the same challenge, a dynamic was started to break up, in such a way that each group could choose their first option challenge, excepting two groups that made their second option. In addition, each group was assigned a random, health or technological tutor, who would be responsible for guiding and supporting the team throughout all process of looking for a solution for the challenge. Each group worked on its challenge daily during the ten days of the Summer School. They did it autonomously or accompanied by their tutor, in the faculty spaces reserved for such purpose or in the place that they deem convenient. The summer school coordinators were responsible for managing the spaces, providing the necessary materials to make the prototype and contacting students with university services for prototyping, such as the 3D printing or the robotics department.

\subsection{Data collection}

To know the perception of the students about the methodology used, an ad hoc questionnaire was designed. In the first place, the questionnaire collected sociodemographic data to know the characteristics of the student such as gender, age, living country, college degree and course. After that, the questionnaire contained 19 questions distributed in 3 general blocks: teaching methodology, tutoring and beliefs and conceptions. Within the teaching methodology block, two subcategories were established, one of general concepts and the second one referring to the utility of the methodology in the acquisition of new competencies. Each item was drafted as an affirmation that students should score from 1 to 6 according to their degree of agreement, where 1 meant in total disagreement and 6 very much in agreement. The answers obtained were fully transcribed and analyzed.

The purpose of the questionnaire was explained, and the informed consent document was presented prior to the administration of the questionnaire. The document contained the objective, the ethical considerations regarding the confidentiality of the data and the right of the student to withdraw from the study at any time without giving any explanation and without this having any impact on him. At the end, 48 students from a total of 60 attendees to the summer school agreed to participate and signed their informed consent.

\section{RESULTS}

A total of 48 students responded to the questionnaire provided. Of these, $54 \%$ were girls $(n=26)$ and $46 \%$ were boys $(n=22)$. The average age was 24.27 years with a range between $19-54$ years. The representation of disciplines was distributed in such a way that $27 \%$ of the participating students corresponded to a background of health and $73 \%$ to the sciences of technology.

The issues that were raised in the video-challenges were diverse and tried to contemplate a wide variety of situations in order to maximize the learning of students. A total of 9 challenges were presented, 3 of which were formulated by patients and 6 by health professionals. Regarding the themes of the challenges, the following were worked out: two of them referred to problems related to mobility within and outside the home of people with reduced mobility, two more to the need for entertainment devices for infants admitted to hospitals for long periods of time and with the aim of reducing their stress, another to devices that facilitate the communication of people with cognitive impairment to others, two other issues were related to usability problems of current medical devices, another proposed the need to generate non-invasive medical imaging systems to increase patient's safety in invasive procedures and, finally, the last one related to needs linked to the rehabilitation of people with physical disabilities in refugees camps.

Table 1 presents the descriptive results corresponding to the results obtained from the questionnaire: 
Table 1. Evaluation survey results

\begin{tabular}{|c|c|c|c|c|}
\hline \multicolumn{2}{|l|}{ Topic } & \multirow{2}{*}{$\begin{array}{l}\text { Item } \\
\text { The information that I was given at the } \\
\text { beginning, was enough to start the } \\
\text { challenge teamwork }\end{array}$} & \multirow{2}{*}{$\frac{\boldsymbol{\mu}}{4,15}$} & \multirow{2}{*}{$\begin{array}{c}\boldsymbol{\sigma} \\
1,07\end{array}$} \\
\hline \multirow[t]{12}{*}{$\begin{array}{l}\text { Teaching } \\
\text { methodology }\end{array}$} & \multirow[t]{4}{*}{ General } & & & \\
\hline & & $\begin{array}{l}\text { The methodology used has responded to } \\
\text { my learning needs }\end{array}$ & 4,38 & 1,27 \\
\hline & & $\begin{array}{l}\text { The video-challenge has allowed the group } \\
\text { to raise new learning questions }\end{array}$ & 4,65 & 1,14 \\
\hline & & $\begin{array}{l}\text { Video-challenge has generated discussion } \\
\text { within the group }\end{array}$ & 5 & 1,05 \\
\hline & \multirow{8}{*}{$\begin{array}{l}\text { Usefulness in } \\
\text { the } \\
\text { acquisition of } \\
\text { competences }\end{array}$} & Organization & 4 & 1,19 \\
\hline & & Leadership / management skills & 4 & 1,29 \\
\hline & & Decision making skills & 4,4 & 1,07 \\
\hline & & Multidisciplinary teamwork & 4,73 & 1,27 \\
\hline & & Creativity and entrepreneurial skills & 4,31 & 1,13 \\
\hline & & Communication skills & 4,71 & 1,09 \\
\hline & & $\begin{array}{l}\text { Conflict management and problem-solving } \\
\text { skills }\end{array}$ & 4,4 & 1,16 \\
\hline & & Confidence & 4,5 & 1,25 \\
\hline \multirow[t]{4}{*}{ Tutoring } & \multirow[t]{4}{*}{ My tutor... } & Has been accessible and dialoguing & 4,4 & 1,43 \\
\hline & & $\begin{array}{l}\text { Has facilitated and promoted the } \\
\text { discussion of the group acting }\end{array}$ & 4,08 & 1,41 \\
\hline & & $\begin{array}{l}\text { Has facilitated the resolution of doubts } \\
\text { related to the theme of the challenge }\end{array}$ & 3,9 & 1,55 \\
\hline & & $\begin{array}{l}\text { Has been a facilitator of the learning } \\
\text { process }\end{array}$ & 3,77 & 1,55 \\
\hline \multirow{3}{*}{\multicolumn{2}{|c|}{ Beliefs and new conceptions }} & $\begin{array}{l}\text { I believe that multidisciplinary teams are } \\
\text { essential in the field of eHealth }\end{array}$ & 5,58 & 0,71 \\
\hline & & $\begin{array}{l}\text { I consider that experiences like the summer } \\
\text { school favour the training of necessary } \\
\text { skills for my professional future in eHealth }\end{array}$ & 5,4 & 0,84 \\
\hline & & I've greatly contributed to the teamwork & 5 & 1,09 \\
\hline
\end{tabular}


Regarding the results presented in Table 1, all the items related to the teaching methodology obtained a score equal to or greater than 4, which reinforces the adequacy of the use of this pedagogical strategy. Of these, the most well-considered item was the ability of video-challenges to generate a discussion within the group $(\mu=5)$, in line with the thesis that the challenge-based methodology promotes a deep reflection on the proposed scenarios. In relation to the acquisition of new competences, the students considered that the methodology had been useful for this purpose, emphasizing the skills of teamwork in multidisciplinary environments $(\mu=4.73)$ and communication $(\mu=4.71)$.

Regarding the function of the tutors, in two items the average score was below the value of 4 , which could be related to the fact that some tutors could not be present throughout the summer school for commitments with their institution of origin. Finally, the scores obtained in the block of beliefs show the importance that students give to experiences like this $(\mu=5.4)$ and the need to train all those competences related to multidisciplinary work teams $(\mu=5.58)$.

\section{CONCLUSIONS}

There are numerous evidences of the importance of higher education in eHealth for the training of professionals who will have to respond to the future social and health challenges of the population. To do this, it is essential to break with the traditional separation between disciplines and to bet on multidisciplinary teams from their own university education.

The experience presented in this article, corresponding to the 3rd summer school of the Eurocampus project, demonstrates the validity of this learning model in the training task of future professionals in eHealth. Among others, it demonstrates the adequacy of the methodology based on real challenges as an effective strategy in learning, demonstrating its ability to generate discussion environments within teams, which encourage creativity and the acquisition of new competencies. Likewise, it has been shown that new generations of students give special importance to their training in multi-disciplinary teams, which they consider essential in the development of their future work.

Finally, the results obtained are challenging for the future: how can teachers make the adaptation and transfer of an expert role to a facilitator role, in such a way that their function is increasingly flexible and adaptable to the needs and concerns of the students.

\section{ACKNOWLEDGEMENTS}

The authors thank the participants (students, teachers and administrators) of the eHealth Eurocampus project - 2016-1-FR01-KA203-023932 (KA2 - Cooperation for innovation and the exchange of good practices). 


\section{REFERENCES}

[1] European Commission, "Population ageing in Europe. Facts, implications an policies", European Commission, 2014. Retrieved from https://ec.europa.eu/research/socialsciences/pdf/policy reviews/kina26426enc.pdf

[2] European Union, "People in the EU: who are we and how do we live", Eurostat Statistical Books, 2015. Retrieved from https://ec.europa.eu/eurostat/documents/3217494/7089681/KS-04-15-567EN-N.pdf/8b2459fe-0e4e-4bb7-bca7-7522999c3bfd

[3] World Health Organization, " Good health adds life to years Global brief for World Health Day 2012", World Health Organization, 2012. Retrieved from https://apps.who.int/iris/bitstream/handle/10665/70853/WHO DCO WHD 2012.2 eng.pdf;jsessio nid=2CED80E993D320B93EDDD11433FEE50A? sequence $=1$

[4] I.A Glinos, "Health professional mobility in the European Union: Exploring the equity and efficiency of free movement", Health policy 119 (12), 2015.

[5] L. Penterman, "E-health enabled integrated care teams, what makes them effective? Interdisciplinary collaboration", Thesis Health Sciences- University of Twente, 2016.

[6] A. Janssen, M. Brunner, M. Keep, M. Hines, S. Vilapakkam Nagarajan, C. Kielly-Carroll, S. Dennis, Z. Mckeough, T. Shaw, "Interdisciplinary eHealth Practice in Cancer Care: A Review of the Literature", International Journal of Environmental Research and Public Health", International Journal of Environmental Research and Public Health 14(11):1289, 2017.

[7] L. van Velsen, J. Wentzel, J. Gemert-Pijnen, "Designing eHealth that Matters via a Multidisciplinary Requirements Development Approach", JMIR research protocols, vol. 2, iss. 1,| e21, 2013.

[8] H. Gilstad, "Toward a comprehensive model of eHealth literacy", In: E.A.A. Jaatun, E. Brooks, K.E. Berntsen, H. Gilstad, M. G. Jaatun (eds)., 63-72., Trondheim Norway: Proceedings of the 2nd European Workshop on Practical Aspects of Health Informatics (PAHI 2014), 2014. Published at http://ceur-ws.org 2014

[9] N. Castell, J. Lobo, E. Insa Calderon, R. Picking, Y. González, S. Abdelaziz, B. Voegel, X. Tous, C. Pattichis, B. Rigaud, " eHealth Eurocampus Project: Preparing innovative ICT professionals", Valencia: INTED 2019 Proceedings, pp. 5560-5564, 2019.

[10]R. Picking, A. Graells Sans, E. Insa Calderon, I. Salinas Bueno, "An evaluation of student perceptions of the effectiveness of multidisciplinary teaching and learning in eHealth", Valencia: INTED2019 Proceedings, pp. 5652-5658, 2019.

[11]M. Nichols, K. Cator, M. Torres. "Challenge Based Learner User Guide". Redwood City, CA: Digital Promise, 2016

[12] Observatorio de innovación educativa, "EduTrends, Aprendizaje Basado en Retos" Instituto Tecnológico de Monterrey, 2016. Retrieved from https://blog.bechallenge.io/aprendizaje-basadoen-retos/ 